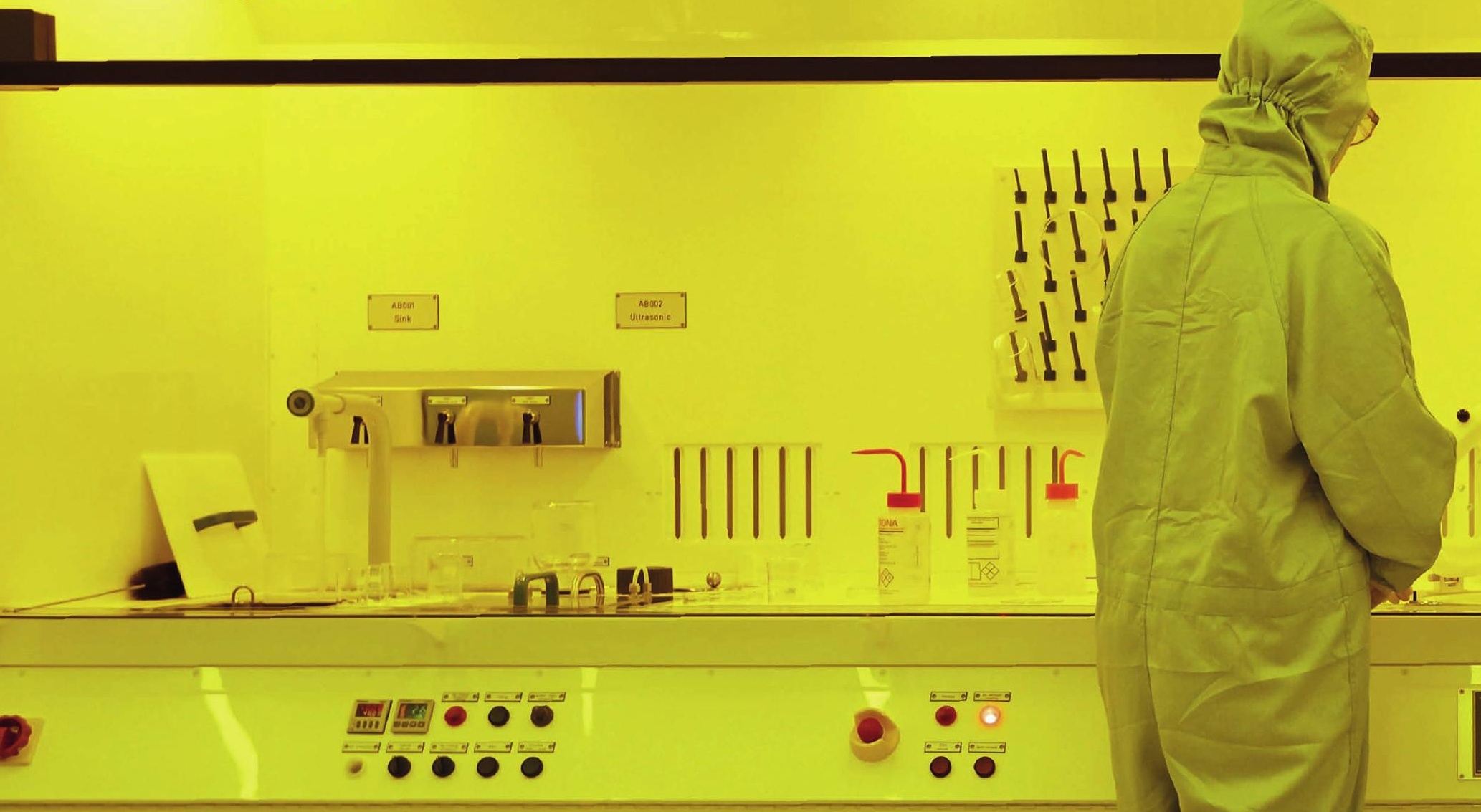

\title{
TRIALS AND TRIBULATIONS
}

\section{Herceptin changed the nature of cancer treatment, but this life-extending drug may never have seen the light of day without parallel breakthroughs on many fronts.}

\section{BY SUJATA GUPTA}

$\mathrm{I}$

n the early 1990s researchers at biotech company Genentech in San Francisco started trialling a trailblazing drug for an aggressive form of breast cancer that affects about one in five women with the disease. At the time, treatment options for these women were highly toxic chemotherapies with harsh side effects that rarely brought the disease under control. The survival rate for this form of cancer, now known as HER2-positive, was also lower than other types of breast tumours. "My goal was to find a way to treat cancer where you can damage the tumour cells with little or no damage to the patient," says researcher
Michael Shepard, who was closely involved with the drug's long development path.

But garnering support for the drug during its development proved difficult. With many in the cancer research field sceptical of its potential, Genentech worried about investing in a failure. Ultimately, trials of the drug, now sold as Herceptin, moved forward. Shepard and others proved it was possible to create drugs, known as monoclonal antibodies, that can selectively target cells that express cancerous genes.

The drug has been used to treat around two million people since it first appeared in clinical trials. Beyond breast cancer, Herceptin "created a new paradigm for how to look for treatments in cancer," says Shepard.

Tracing the history of this life-extending drug reveals its creation was contingent on multiple parallel developments over many decades: scientists exploring the basis of cancer and immune function, the development of so-called humanized antibodies, and clinical researchers pushing executives to persevere with a new class of cancer treatment. "The main message I took away from this story was how close the drug, which became an enormous success, came to not being made," says science journalist Robert Bazell, who wrote the book Her-2: The Making of Herceptin, a 


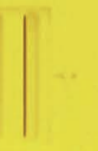

Revolutionary Treatment for Breast Cancer.

The Herceptin story begins more than a century ago, when researchers started searching for ways to selectively destroy cancer cells. By the 1970 s, a team in California had discovered that genes with the potential to trigger cancer so-called oncogenes - lie within us, and that it might be possible to shut them off.

\section{SELECTIVE ANNIHILATION}

Around that time, an immunologist, Lloyd Old, from Memorial Sloan Kettering Cancer Center in New York City found that a cell signalling protein known as tumour necrosis factor (TNF) killed tumour cells in mice, but left healthy cells intact. When Shepard heard this, he started investigating TNF.

In the early 1980s, Shepard's team obtained as many tumour cell types as possible. To Shepard's surprise, tumour cells continued growing in half of his samples injected with TNF. He began looking into how the tumour cells were evading it.

Shepard soon discovered that slowgrowing cancers turned aggressive and resistant to TNF when adorned with certain vitamins and hormones that nurture the growth of cells.
Growth factors, he realized, might be the mechanism protecting tumour cells.

Other researchers at Genentech were also looking at the link between growth factors and cancer. In September 1985, molecular biologist, Axel Ullrich, published a study in Science linking cancer to the growth factor HER2, a protein found on cell surfaces that controls cell

\section{"SCIENCE WORKS BY INDIVIIDUALS PADDLLNG UPSTREAM, AND MIKEHAD TO PADLLEUPSTREAM:}

growth and division. Stuart Aaronson at the National Cancer Institute in Bethesda, Maryland published similar results around the same time, although Aaronson's team went a step further by linking HER 2 to breast cancer. Both labs also cloned the gene that makes HER2, also called HER2.

Serendipitously, Robert Hudziak, a post-doctoral fellow in Ullrich's lab came across Shepard's paper connecting over-expression of growth factors to more aggressive cancers. Hudziak walked over to Shepard's lab and told him about his team's efforts to identify and then clone HER2. Hudziak had found that cancer cells that overexpressed HER2 receptors turned aggressive. "Axel had been trying to convince Genentech to pursue growth factors for a long time. This was his first chance to emerge from the muck," recalls Shepard. "We had a common interest."

Shepard and Hudziak began working together to find a way to dial back the overexpression of HER2. Fortuitously, Genentech had a molecule to do this. It was company protocol to create antibodies against any cloned gene. When Shepard and Hudziak delivered the antibody for HER2, known as 4D5, cells over-expressing the gene became sensitive both to TNF and to macrophages capable of gobbling them up. "By turning down HER2 activity with the antibody, you could allow the patient's immune system to get back to work killing tumour cells," Shepard says. 
Tracing the history of Herceptin through key publications shows the drug's creation was contingent on early discoveries in immunology and cell function that occurred decades before scientists and a drug company set about developing the blockbuster therapy.

LATE 1800s
Immunologist Paul
Ehrlich uses clothing
dyes to stain cells,
discovering certain
dyes stain tumour
cells. Ehrlich didn't
know those deeper
stains were due to
excess DNA in the
tumour cells, but
thought it might be
possible to target
those cancerous cells
with drugs in future.
Ehrlich, P. University
of Leipzig, doctoral
dissertation (1878)

1950s-1960s

Biochemist

Stanley Cohen and neurobiologist Rita Levi-Montalcini discover growth factors - the vitamins and hormones that help cells grow. This paves the way for subsequent work linking over-expression of growth factors to cancer. Cohen and Levi-Montalcini win the Nobel Prize in Physiology or Medicine in 1986.

\section{5}

Physician

and cancer researcher Lloyd Old reports that Tumor Necrosis Factor (TNF), a protein vital for immune signaling, causes tumors in mice to necrose or die.

Carswell EA et al. Proc Natl Acad Sci U S A 72, 3666-70 (1975)

\section{6}

Scientists in

California

discover genes with the potential to trigger cancer lie within OUR cells. Finding and shutting off these oncogenes means scientists can investigate how to stop tumor cells from spreading.

This and related studies lead to UCSF virologists J. Michael Bishop and Harold

Varmus winning the Nobel Prize in Physiology or Medicine in 1989.

Stehelin D et al.

Nature 260, 170-173 (1976)
1984

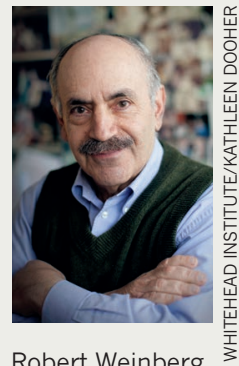

a biomedical researcher at MIT, reports that brain tumours in rats contain an oncogene he calls neu, which later becomes known as neu/HER2.

Weinberg, R. et al. Nature 312, 513-516 (1984)
1985

Multiple labs clone HER2 with one group linking over-expression of HER2 protein receptors to breast cancer.

Schechter, AL. et al. Science 229, 976-8 (1985)

King, CR. et al. Science 229, 974-6 (1985)
1987

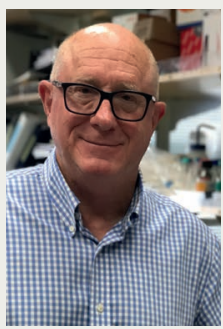

Genentech cancer researcher, Michael Shepard, and team discover that over-expression of growth factors makes some tumour cells more aggressive by allowing them to avoid Tumour Necrosis Factor.

Sugarman, BJ. et al. Cancer Research 47, 780-786 (1987)

\section{HUMAN TESTING}

Genentech's findings were limited to mouse and cell culture models. To translate those results for humans, Shepard needed to find patients with a type of cancer that overexpressed HER2. Enter Bill McGuire, an oncologist at the University of Texas in San Antonio, who had amassed an extensive human tumour bank, and Dennis Slamon, an oncologist at the University of California, Los Angeles.

Slamon was familiar with Aaronson's research linking HER2 to breast cancer, and wanted to test if those findings could be extended to actual patients. Sure enough, the researchers discovered that HER2 was overexpressed in $30 \%$ of the 189 breast cancer samples they investigated. "Genentech had identified the antibody that could be used and Slamon had identified the patients to use it with," Shepard says.

Despite the drug's promise, executives at Genentech were nervous. The company had already tested other cancer drugs, including TNF, that had failed and using antibodies to treat cancer was a new idea. Another failed drug could bankrupt the company. "Genentech was not interested in antibodies," recalls Marc Feldmann, an immunologist at the University of Oxford and independent consultant on the project. "They tried to close the programme on multiple occasions.” A Genentech spokesperson disputed this version of events, saying the company supported monoclonal antibody therapy.

Slamon and Shepard, who had begun collaborating, found an ally in Bill Young, a senior manager at Genentech. "My mother had gone through breast cancer and passed away," Young says. "I was always a big supporter of the project."

Slamon also garnered vital support from the wife of a former patient. Years earlier, he had treated television executive, Brandon Tartikoff, for Hodgkin's lymphoma. (Tartikoff died from the disease in 1997). When Tartikoff's wife, philanthropist Lilly Tartikoff, heard about Slamon's breast cancer project and its many challenges, she convinced Revlon, the cosmetic company, to contribute millions toward the research. Slamon became one of the most highly financed researchers at UCLA, Bazell says. "He had a lot more clout."
Genentech agreed to conduct a preliminary experiment. Because the only antibody the company had against HER2 was for mice, it could be only given to humans once before the body rejected it. Genentech wanted to see what would happen if women with both HER2-positive and HER2-negative cancer received a single dose of that mouse antibody. If Shepard and Slamon could show, through diagnostic images, that the antibody localized to tumours in HER2-positive patients only, Genentech would move forward with a formal trial. The experiment worked. Images made clear the antibody was targeting tumours in HER2-positive women only.

In their rush to move forward with clinical trials, Slamon and Shepard never published the results from that preliminary study. "We were all in such a hurry to get from the mouse antibody to the human one, so we could do a real trial," Shepard says.

\section{FIRST TRIALS}

By 1991, Genentech had hired Paul Carter, a leading antibody engineer, who had humanized $4 \mathrm{D} 5$ by grafting parts of a mouse 
Phase I, II, II trials of Herceptin.

1992-1996

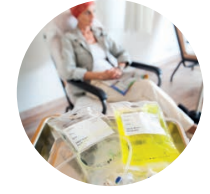

(1992-19
1987

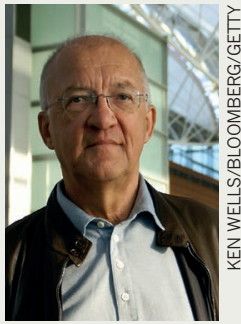

Axel Ullrich's lab at Genentech shows that over-expression of HER2 makes tumours more aggressive.

Hudziak et al. Proc Natl Acad Sci U S A 84 7159-63 (1987)

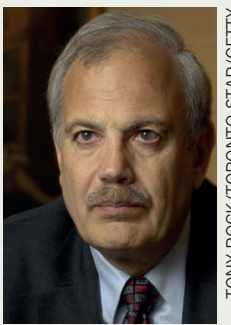

Oncologists Bill McGuire and Dennis Slamon, show that HER2 is over-expressed in a subset of breast cancer patients.

Slamon, DJ. et al. Science 235, 177-82 (1987)

\section{9}

Genentech's Robert Hudziak and Shepard show that the monoclonal antibody 4D5 restores HER2-positive breast tumour cells' sensitivity to Tumour Necrosis Factor.

Hudziak et al. Mol Cell Biol 9(3), 1165 (1989)
1990

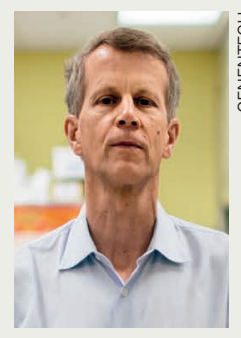

Genentech's Paul

Carter develops a

humanized version of the HER2 target antibody, a

Herceptin (trastuzumab) precursor.

Carter, P. et al. Proc Natl Acad Sci U S A 89, 4285 4289 (1992)

FDA approves Herceptin in combination with chemotherapy paclitaxel for women with metastatic HER2-positive breast cancer. The drug comes with a warning about possible heart problems.

\section{8}

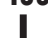

1996

1998

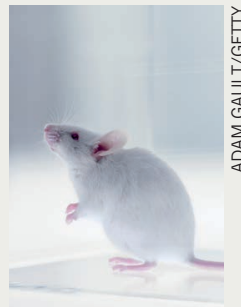

Sloan Kettering team report shows that in mice

trastuzumab in combination with

chemotherapy works better than trastuzumab in isolation.

Baselga, J. et al.

Cancer Research

$58,2825-31$

(1998)
2001

A retrospective analysis shows women receiving paclitaxel and trastuzumab have a lower incidence of heart problems than women receiving trastuzumab with other chemotherapies.

Slamon, DJ. et al. N Engl J Med 344, 782-792 (2001) antibody on to a human antibody. Genentech rolled out a phase I trial of the drug a year later. "Science works through individuals paddling upstream, and Mike had to paddle upstream," says Feldman.

As testing moved forward, problems persisted. One of the Phase III trials was so poorly designed that some doctors stopped referring patients, says Larry Norton, an oncologist involved in early trials. Among several issues, the drug, generic name trastuzumab, wasn't being paired with the chemotherapy drug paclitaxel (sold as Taxol), a combination shown to be effective in mice. Moreover, by that point it was becoming clear that trastuzumab could trigger serious heart problems. Those side-effects appeared to be elevated in women taking the chemotherapy anthracycline. After meetings in 1996 and 1997, Norton and others convinced Genentech scientists to overhaul the study. "Had we not done that, we might not have a drug," says Norton, now medical director of the Evelyn H. Lauder Breast Center at Sloan Kettering. (Shepard disagrees, saying that oncologists simply had not heard of the drug, which Genentech remedied through a comprehensive marketing campaign).

All told, 900 women participated in clinical trials of the drug over seven years. In 1998, the results of another phase III clinical trial

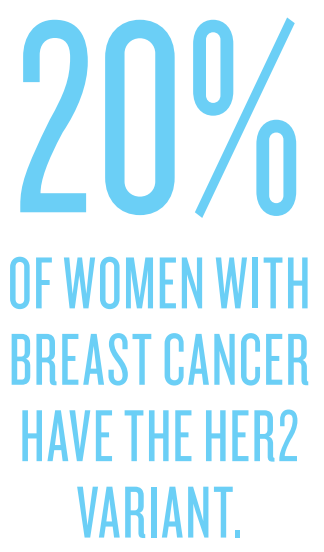

showed that, compared to chemotherapy alone, pairing trastuzumab with chemotherapy reduced the risk of dying within 30 months by about $20 \%$. That finding cleared the way for the
US Food and Drug Administration to approve Herceptin, in conjunction with paclitaxel for women with metastatic HER2-positive breast cancer. Subsequent studies showed the drug could also be used in earlier stages and today, the prognosis of women with stage 1 to stage 3 HER2-positive breast cancer has switched from poor to good.

Many researchers have continued investigating HER genes, discovering and cloning three other HER receptors. That has led to newer drugs and drug combinations. Numerous clinical trials are also underway to see if Herceptin can shrink tumours in HER2negative patients.

At the time the Herceptin trial was underway, similar monoclonal antibody drugs were in the pipeline, but they were in limbo waiting for the go-ahead from the FDA. "There was a big traffic jam," Shepard says. The FDA's approval of Herceptin "opened doors for new drugs," including cetuximab, a monoclonal antibody to treat colorectal, lung, and head and neck cancers. Owing to Herceptin's enormous success, finding targeted cancer treatments has become the norm. 